\title{
REVIEW
}

\section{The influence of genomics and proteomics on the development of potential vaccines against meningococcal infection}

\author{
John E Heckels*t and Jeannette N Williams ${ }^{\dagger}$
}

\begin{abstract}
There is a particular need for an effective vaccine against life-threatening meningitis and septicemia caused by Neisseria meningitidis (meningococcus) serogroup B strains. Vaccine strategies incorporating capsular polysaccharide have proved effective against other meningococcal serogroups, but are not applicable to serogroup B. Attention has therefore focused on the subcapsular outer membrane protein antigens as potential vaccine components. The sequencing of genomes from three serogroups and the availability of the corresponding translated protein databases, combined with the development of sensitive proteomic techniques, have opened up new avenues of meningococcal vaccine research. This has resulted in the identification of potential candidate antigens for incorporation into multicomponent meningococcal vaccines.
\end{abstract}

\section{Background}

The development of an effective vaccine against all strains of Neisseria meningitidis (meningococcus), the major cause of life-threatening bacterial meningitis and septicemia, is a priority for infectious disease research. Meningococci can be classified into serogroups based on the structure of their extracellular capsular polysaccharide, with serogroups $\mathrm{B}$ and $\mathrm{C}$ being traditionally responsible for the majority of invasive disease in most temperate countries, and serogroup A causing epidemic infections in sub-Saharan Africa.

${ }^{*}$ Correspondence: jeh@soton.ac.uk

Molecular Microbiology Group, Sir Henry Wellcome Laboratories, Division of Infection, Inflammation and Immunity, University of Southampton Faculty of Medicine, Mailpoint 814, Southampton General Hospital, Southampton SO16 6YD, UK

${ }^{+}$Contributed equally
The first generation of vaccines contained purified polysaccharides from serogroups $\mathrm{A}$ and $\mathrm{C}$ that induced antibodies that promoted complement-mediated serum bactericidal activity (SBA), the correlate of protective immunity, against the respective serogroups. Tetravalent polysaccharide vaccines were later produced by the addition of serogroups $\mathrm{Y}$ and W135. However, such vaccines suffer from poor immunogenicity as a consequence of the inability of polysaccharide antigens to induce an effective T-helper-cell response. In adults, they produce only a short-lived antibody response and fail to induce immunological memory. Furthermore, they are non-immunogenic in infants, the main potential target group for meningococcal vaccines. Second-generation vaccines were subsequently developed in which the capsular polysaccharides were covalently linked to carrier proteins in order to induce a T-helper-cell response. Such polysaccharide vaccines produce a long-lived IgG response and induce immunological memory even in infants. The first such vaccine, a serogroup $C$ conjugate, was introduced into the UK immunization program in 1999 and has been extremely effective in reducing cases of serogroup C infections [1].

Unfortunately, none of the above strategies have been applicable to infection caused by serogroup B meningococci, which is the major serogroup associated with invasive disease in most western countries. The serogroup B capsular polysaccharide is non-immunogenic even in adults, due to molecular mimicry of neural cell adhesion molecules expressed on developing fetal brain tissue [2]. Alternative strategies have focused on the vaccine potential of subcapsular antigens. Experimental vaccines have been based on outer membrane (OM) 'blebs' released from the surface of meningococci during growth and from which toxic lipopolysaccharide has been selectively removed by extraction with deoxycholate detergent. Such outer membrane vesicle (OMV) vaccines have been used in attempts to control outbreaks of serogroup B infection in countries such as Norway, Cuba and New Zealand when epidemics have been caused by one predominant serosubtype [3-5]. The success of such 
vaccines has been limited by problems, including: a short duration of protection, poor immunogenicity in children, and variable responses in individuals to the different proteins present in the vesicles [6,7]. Furthermore, the main protective component is believed to be the PorA outer membrane protein [8], which varies between strains and so generates a large number of serosubtype differences that are expressed independently of serogroup. The immunity induced is therefore largely serosubtype specific, and a vaccine based on such a strategy would necessarily have to be prepared from multiple strains and the composition tailored for geographical location and adjusted over time to match the changing incidence of serosubtypes [9].

An effective vaccine against serogroup B meningococci should induce immunity against strains of a wide range of serosubtypes. The contribution of the PorA protein to the protective effect of OMV vaccines is illustrated by the predominantly serosubtype specificity of the resulting SBA. However, analysis of the immune response to OMV vaccines $[10,11]$ and studies of the development of natural immunity induced by colonization with meningococci [12] have suggested that a minor component of the SBA is cross-reactive against heterologous serosubtypes. Unfortunately, at the time of these studies, the limitations of available technology meant that the identity of the antigen(s) responsible for potential cross-reactive immunity could not be determined.

\section{Genomic approaches}

The search for meningococcal antigens capable of inducing cross-reactive immunity has been revolutionized by the availability of complete genome sequences, and the resulting predicted proteins, from meningococcal strains of serogroups A, B and C [13-15].

The first approach has been the use of in silico analysis of the predicted proteome of serogroup B strain MC58 to identify putative candidate vaccine antigens; this approach has been dubbed 'reverse vaccinology'. Pizza and colleagues [16] identified 570 potential open reading frames that encode proteins predicted to be either surface exposed or exported from the bacteria, and they were able to express 350 of these as fusion proteins. Antisera raised against these proteins were tested for SBA and cross-reactivity, leading to the identification of seven proteins as potential vaccine antigens. Five of these were chosen for large-scale expression and incorporated into an experimental human vaccine. Immunization of mice with the pentavalent vaccine induced a bactericidal immune response against a range of strains tested [17]. Phase III clinical trials are underway with a similar vaccine that additionally incorporates OMV [18]. Subsequently, genome sequences of other Neisseria species have become available, and Pajon and colleagues [19] have exploited these together with a more intensive bioinformatic approach to identify five additional antigens that are also able to induce a bactericidal immune response to meningococci.

\section{Proteomic analysis}

The availability of genome sequences and the corresponding translated protein databases have enabled studies on the meningococcal proteome, particularly the detailed composition of outer membrane fractions. In early studies, Frasch and colleagues [20] were able to distinguish only five major classes of proteins in outer membrane preparations from meningococci. Subsequently, additional proteins were identified that were present in lower amounts or only expressed when the bacteria had been grown under nutrient limitation (reviewed in [21]). The total number of proteins identified in outer membrane preparations remained relatively few until the development of more sensitive proteomic methods. This combined with the availability of the translated genome sequences has enabled much more detailed study of outer membrane preparations and the vesicle/vaccine preparations derived from them by deoxycholate extraction. One-dimensional SDS-PAGE of an OMV vaccine preparation followed by tandem mass spectrometry (MS/MS) identified 40 proteins, including 7 that had previously been identified as vaccine candidates [22]. Replacing SDS-PAGE with two-dimensional electrophoresis increased the number of proteins identified to 74 [23].

Further sensitivity can be obtained using SDS-PAGE and nanocapillary liquid chromatography-tandem mass spectrometry (GeLC-MS/MS). Proteins are separated on a conventional one-dimensional SDS-PAGE gel, which is then cut into slices that are subjected to in situ proteolytic digestion. The resulting peptides are separated by reverse-phase liquid chromatography and then applied to a tandem mass spectrometer. Proteins are identified by comparison of the peptide fragments with the sixfold translated genome database. This technique overcomes the problems of two-dimensional gels associated with poor solubility of membrane proteins and has the additional advantage of providing an indication of relative abundance based on the number of peptide fragments identified per protein. Using this technique, Vaughan et al. [24] identified 125 potential proteins in an OMV vaccine and noted significant differences in a similar preparation from the related non-pathogen Neisseria lactamica, which has been suggested as an alternative vaccine. Williams et al. [25] used GeLC-MS/MS to compare an OM preparation with the corresponding OMV vaccine preparation obtained by deoxycholate extraction. A total of 236 proteins were identified in the OM preparation, and the PSORTb algorithm [26] was used to 
predict their expected location within the cell. Only 15 of the identified proteins were predicted to have an OM location but these included all of those well established as major components of the outer membrane. The proteins not predicted to have an OM location were predominantly periplasmic, cytoplasmic, or of unknown location, while relatively few cytoplasmic membrane proteins were detected. The major proteins present were those that had previously been identified as the major components of the OM, including PorA, PorB, Opa, Opc, Rmp and PilQ. Interestingly, several proteins that had previously been suggested as potential vaccine candidates were not detected in either OM or OMV preparations; these included AspA, GNA2132, NadA, and GNA2001. It is not possible to determine whether the 'non-OM proteins' detected in the preparations occur in a natural association with the $\mathrm{OM}$ or whether they arise by 'contamination' during the isolation process. However, proteomic analysis has shown that they are certainly present in the OMV vaccines that have been used for human immunization [22,25].

An alternative strategy to the use of deoxycholate to deplete toxic lipopolysaccharide from OM preparations is to produce OM from a lipopolysaccharide-deficient mutant. Proteomic analysis of such a preparation by GeLC-MS/MS revealed significant differences from OMV prepared conventionally with increased levels of several nonmembrane proteins, particularly those of the tricarboxylic acid cycle [25]. The possible effects of these differences in protein content between the two vaccines are unknown.

\section{Immunoproteomics}

The ability to combine the proteomic approach with the availability of animal or human sera with known bactericidal activity has facilitated an immunoproteomic approach to the identification of possible vaccine candidates.

Mendum et al. [27] used two-dimensional immunoblotting to identify antigens recognized by sera from patients recovering from meningococcal infection. A total of 33 proteins were identified that reacted with acute and/or convalescent sera, although it was not possible to correlate protein reactivity with the bactericidal activity of the sera. Twenty-seven of these proteins were produced in Escherichia coli and used for immunization of mice with Freund's adjuvant. Although none of the resulting sera showed bactericidal activity, this may be due to a failure to refold the recombinant proteins into a native conformation, since the antigen list contained PorA protein, which others have shown to induce high levels of bactericidal activity after refolding into liposomes.

In a similar two-dimensional immunoblotting study, Williams et al. [25] were able to utilize a panel of sera with known bactericidal activity and corresponding colonizing strains from a longitudinal study of meningococcal carriage in new students entering a university hall of residence. Individuals who became colonized with serogroup B meningococci developed bactericidal activity not only against the homologous colonizing strain but also against heterologous strains. Paired sera from colonized individuals were analyzed by immunoproteomic analysis using both homologous and heterologous OM preparations. Immunoblots were reacted with sera, at a standard dilution, taken from the individual pre-colonization and post-colonization. In each case the raised bactericidal antibody activity was always associated with increased reactivity, but the number and intensity of reactions to different meningococcal proteins varied between students and between strains. Proteins on the reference gel were matched to the immunoreactive spots, excised, digested with trypsin, subjected to MS/ MS, and identified by searching against a translation of the MC58 genome. This resulted in the identification of 43 proteins, which included well-established antigens such as PorA and PorB, as well as novel proteins. Such proteins associated with the development of crossreactive immunity to serogroup $B$ meningococcal infection represent potential targets for the development of effective vaccines against serogroup $B$ meningococcal infection [28]. Previous studies with both PorA and PorB produced as recombinant proteins and refolded into liposomes have demonstrated their ability to induce serum bactericidal activity against homologous strains $[29,30]$. Similar studies with the newly identified vaccine candidates will reveal their potential for inducing a potentially protective and cross-reacting immune response against serogroup B (and other serogroup) meningococci.

\section{Conclusions}

The sequencing of meningococcal genomes and the availability of the corresponding protein databases, combined with sensitive modern technology, have opened up exciting new avenues in meningococcal vaccine research. At least one vaccine based on information gleaned from proteomics and genomics is undergoing clinical trials [18] and others are currently being planned. It is likely that these technologies will continue to inform the field in the identification of proteins associated with the development of immunity and in the elucidation of their role in pathogenesis of meningococcal infection. Hopefully, these approaches will bear fruit in the search for an effective vaccine against a devastating infection.

\footnotetext{
Abbreviations

GeLC-MS/MS, gel enhanced nanocapillary liquid chromatography-tandem mass spectrometry; MS/MS, tandem mass spectrometry; OM, outer membrane; OMV, outer membrane vesicle; SBA, serum bactericidal activity.
}

Competing interests

The authors declare that they have no competing interests. 


\section{Authors' contributions}

Both authors contributed equally to the preparation of the manuscript.

\section{Authors' information}

JEH is Professor of Molecular Microbiology, and JNW is Research Fellow in the Molecular Microbiology Group, Division of Infection, Inflammation and Immunity, University of Southampton Medical School.

\section{Acknowledgements}

Work in the authors' laboratory has received funding from Meningitis UK, Wessex Medical Research and the University of Southampton.

Published: 22 July 2010

\section{References}

1. Ramsay ME, Andrews N, Kaczmarski EB, Miller E: Efficacy of meningococcal serogroup C conjugate vaccine in teenagers and toddlers in England. Lancet 2001, 357:195-196.

2. Finne J, Leinonen M, Makela PH: Antigenic similarities between brain components and bacteria causing meningitis. Implications for vaccine development and pathogenesis. Lancet 1983, 2:355-357.

3. Bjune G, Hoiby EA, Gronnesby JK, Arnesen O, Holstfredriksen J, Halstensen A, Holten E, Lindbak AK, Nokleby H, Rosenqvist E, et al:. Effect of outer membrane vesicle vaccine against group $B$ meningococcal disease in Norway. Lancet 1991, 338:1093-1096.

4. Oster P, Lennon D, O'Hallahan J, Mulholland K, Reid S, Martin D: MeNZB (TM): a safe and highly immunogenic tailor-made vaccine against the New Zealand Neisseria meningitidis serogroup B disease epidemic strain. Vaccine 2005, 23:2191-2196.

5. Sierra GVG, Campa HC, Varcacel NM, Garcia IL, Izquierdo PL, Sotolongo PF, Casanueva GV, Rico CO, Rodriguez CR, Terry MH: Vaccine against group B Neisseria meningitidis: Protection trial and mass vaccination results in Cuba. NIPH Annals 1991, 14:195-210.

6. Boslego J, Garcia J, Cruz C, Zollinger W, Brandt B, Ruiz S, Martinez M, Arthur J, Underwood P, Silva W, et al.: Efficacy, safety, and immunogenicity of a meningococcal group $\mathrm{B}(15 \mathrm{P} 1.3)$ outer membrane protein vaccine in Iquique, Chile. Vaccine 1995, 13:821-829.

7. Milagres LG, Ramos SR, Sacchi CT, Melles CEA, Vieira VSD, Sato H, Brito GS, Moraes JC, Frasch CE: Immune response of Brazilian children to a Neisseria meningitidis serogroup $B$ outer membrane protein vaccine: comparison with efficacy. Infect Immun 1994, 62:4419-4424.

8. Wedege E, Hoiby EA, Rosenqvist E, Bjune G: Immune responses against major outer membrane antigens of Neisseria meningitidis in vaccinees and controls who contracted meningococcal disease during the Norwegian serogroup B protection trial. Infect Immun 1998, 66:3223-3231.

9. Frasch CE, van Alphen L, Holst J, Poolman JT, Rosenqvist E: Outer membrane protein vesicle vaccines for meningococcal disease. In Meningococcal Vaccines. Edited by Edited by Pollard AJ, Maiden MCJ. Totowa, New Jersey: Humana Press; 2001:81-107.

10. Milagres LG, Gorla MC, Sacchi CT, Rodrigues MA: Specificity of bactericidal antibody response to serogroup B meningococcal strains in Brazilian children after immunisation with an outer membrane vaccine. Infect Immun 1998, 66:4755-4761.

11. Rouppe van der Voort EM, van Dijken H, Kuipers B, van der Biezen J, van der Ley P, Meylis J, Claassen I, Poolman J: Human B- and T-cell responses after immunisation with a hexavalent PorA meningocccal outer membrane vesicle vaccine. Infect Immun 1997, 65:5184-5190

12. Jordens JZ, Williams JN, Jones GR, Christodoulides M, Heckels JE: Development of immunity to serogroup B meningococci during carriage of Neisseria meningitidis in a cohort of university students. Infect Immun 2004, 72:6503-6510.

13. Parkhill J, Achtman M, James KD, Bentley SD, Churcher C, Klee SR, Morelli G, Basham D, Brown D, Chillingworth T, Davies RM, Davis P, Devlin K, Feltwell T, Hamlin N, Holroyd S, Jagels K, Leather S, Moule S, Mungall K, Quail MA, Rajandream MA, Rutherford KM, Simmonds M, Skelton J, Whitehead S, Spratt BG, Barrell BG: Complete DNA sequence of a serogroup A strain of Neisseria meningitidis Z2491. Nature 2000, 404:502-506

14. Tettelin H, Saunders NJ, Heidelberg J, Jeffries AC, Nelson KE, Eisen JA, Ketchum KA, Hood DW, Peden JF, Dodson RJ, Nelson WC, Gwinn ML, DeBoy R, Peterson JD, Hickey EK, Haft DH, Salzberg SL, White O, Fleischmann RD, Dougherty BA, Mason T, Ciecko A, Parksey DS, Blair E, Cittone H, Clark EB, Cotton MD, Utterback TR, Khouri H, Qin H, et al:: Complete genome sequence of Neisseria meningitidis serogroup B strain MC58. Science 2000, 287:1809-1815.
15. Bentley SD, Vernikos GS, Snyder LA, Churcher C, Arrowsmith C, Chillingworth T, Cronin A, Davis PH, Holroyd NE, Jagels K, Maddison M, Moule S, Rabbinowitsch E, Sharp S, Unwin L, Whitehead S, Quail MA, Achtman M, Barrell B, Saunders NJ Parkhill J: Meningococcal genetic variation mechanisms viewed through comparative analysis of serogroup C strain FAM18. PLoS Genet 2007, 3:e23.

16. Pizza M, Scarlato V, Masignani V, Giuliani MM, Aricò B, Comanducci M, Jennings GT, Baldi L, Bartolini E, Capecchi B, Galeotti CL, Luzzi E, Manetti R, Marchetti E, Mora M, Nuti S, Ratti G, Santini L, Savino S, Scarselli M, Storni E, Zuo P, Broeker M, Hundt E, Knapp B, Blair E, Mason T, Tettelin H, Hood DW, Jeffries AC, et al.: Identification of vaccine candidates against serogroup $B$ meningococcus by whole-genome sequencing. Science 2000, 287:1816-1820.

17. Giuliani MM, Adu-Bobie J, Comanducci M, Aricò B, Savino S, Santini L, Brunelli B, Bambini S, Biolchi A, Capecchi B, Cartocci E, Ciucchi L, Di Marcello F, Ferlicca F, Galli B, Luzzi E, Masignani V, Serruto D, Veggi D, Contorni M, Morandi M, Bartalesi A, Cinotti V, Mannucci D, Titta F, Ovidi E, Welsch JA, Granoff D, Rappuoli R, Pizza M: A universal vaccine for serogroup B meningococcus. Proc Natl Acad Sci U S A 2006, 103:10834-10839.

18. Lucidarme J, Comanducci M, Findlow J, Gray SJ, Kaczmarski EB, Guiver M, Vallely PJ, Oster P, Pizza M, Bambini S, Muzzi A, Borrow R: Characterisation of $\mathrm{fHbp}$, nhba (gna2132), nadA, porA and sequence type in group $B$ meningococcal case isolates collected in England and Wales during January 2008 , and potential coverage of an investigational group B meningococcal vaccine. Clin Vaccine Immunol 2010, 17:919-929

19. Pajon R, Yero D, Niebla O, Climent Y, Sardinas G, Garcia D, Perera Y, Llanes A, Delgado M, Cobas K, Caballero E, Taylor S, Brookes C, Gorringe A: Identification of new meningococcal serogroup $B$ surface antigens through a systematic analysis of neisserial genomes. Vaccine 2009, 28:532-541.

20. Tsai CM, Frasch CE, Mocca LF: Five structural classes of major outermembrane proteins in Neisseria meningitidis. J Bacteriol 1981, 146:69-78.

21. Derrick JP, Heckels JE, Virji M: Major outer membrane proteins of meningococci. In Meningococcal disease: Infection Biology, Vaccination, Clinical Management. Edited by Edited by Frosch M, Maiden MC. Weinheim: Wiley-VCH; 2006:181-200.

22. Vipond C, Wheeler JX, Jones C, Feavers IM, Suker J: Characterization of the protein content of a meningococcal outer membrane vesicle vaccine by polyacrylamide gel electrophoresis and mass spectrometry. Hum Vaccin 2005, 1:80-84.

23. Vipond C, Suker J, Jones C, Tang C, Feavers IM, Wheeler JX: Proteomic analysis of a meningococcal outer membrane vesicle vaccine prepared from the group B strain NZ98/254. Proteomics 2006, 6:3400-13.

24. Vaughan TE, Skipp PJ, O'Connor CD, Hudson MJ, Vipond R, Elmore MJ, Gorringe AR: Proteomic analysis of Neisseria lactamica and Neisseria meningitidis outer membrane vesicle vaccine antigens. Vaccine 2006, 24:5277-5293.

25. Williams JN, Skipp PJ, Humphries HE, Christodoulides M, O'Connor CD, Heckels JE: Proteomic analysis of outer membranes and vesicles from wild-type serogroup B Neisseria meningitidis and a lipopolysaccharide deficient mutant. Infect Immun 2007, 75:1364-1372.

26. Gardy JL, Laird MR, Chen F, Rey S, Walsh CJ, Ester M, Brinkman FS: PSORTb v.2.0: expanded prediction of bacterial protein subcellular localization and insights gained from comparative proteome analysis. Bioinformatics 2004, 21:617-623.

27. Mendum TA, Newcombe J, McNeilly CL, Mcfadden J: Towards the immunoproteome of Neisseria meningitidis. PLOS ONE 2009, 4:e5940.

28. Williams JN, Skipp PJ, O'Connor CD, Christodoulides M, Heckels JE: Immunoproteomic analysis of the development of natural immunity in subjects colonized by Neisseria meningitidis reveals potential vaccine candidates. Infect Immun 2009, 77:5080-5089.

29. Wright JC, Williams JN, Christodoulides M, Heckels JE: Immunisation with recombinant PorB outer membrane protein induces a bactericidal immune response against Neisseria meningitidis. Infect Immun 2002, 70:4028-4034

30. Humphries HE, Williams JN, Blackstone R, Jolley KA, Yuen HM, Christodoulides $M$, Heckels JE: Multivalent liposome-based vaccines containing different serosubtypes of PorA protein induce cross-protective bactericidal immune responses against Neisseria meningitidis. Vaccine 2006, 24:36-44.

doi:10.1186/gm164

Cite this article as: Heckels JE, Williams JN: The influence of genomics and proteomics on the development of potential vaccines against meningococcal infection. Genome Medicine 2010, 2:43. 